\title{
Towards an Entrepreneurial Model of University: Issues and Challenges in Managing Intellectual Property (IP) and Its Commercialization $(\mathrm{C})$
}

\author{
Abdul Rauf Ambali ${ }^{2,4}$ Abdul Rahman Omar, ${ }^{3,5}$, Ahmad Naqiyuddin Bakar ${ }^{2,3,4}$, \\ Roseleena Jaafar, ${ }^{5,7}$, Mohd Fadzil Mohd Idris ${ }^{6}$, Zulkifli Abd Majid ${ }^{5,7}$, Kamarol \\ Baharen Mohd Rom ${ }^{1,7}$ \\ ${ }^{1}$ Academy of Language Studies, UiTM, Shah Alam, Selangor \\ ${ }^{2}$ Centre for Biodiversity and Sustainable Development, UiTM, Puncak Alam, Selangor \\ ${ }^{3}$ Centre for Strategic Planning and Information (CSPI), UiTM Shah Alam, Selangor \\ ${ }^{4}$ Faculty of Administrative Science and Policy Studies, UiTM Shah Alam, Selangor \\ ${ }^{5}$ Faculty of Mechanical Engineering, UiTM Shah Alam, Selangor \\ ${ }^{6}$ Higher Education Leadership Academy (AKEPT) \\ ${ }^{7}$ Research Innovation Business Unit, UiTM, Shah Alam, Selangor
}

\begin{abstract}
There are a number of procedures required by researchers to undergo before the outcome of their research products known as intellectual properties (IP) can get to the market for economic values. In this volume, researchers examine the interrelationships among these procedures, policy issues and communication flow with commercialization experienced by researchers in selected Malaysian higher institutions of learning that engaged in IP and commercialization. Methodologically, the study has been approached from quantitative perspective using questionnaire. The results from the study have shown that a positive significant relationship exists between the IP-Commercialization procedures and internal critical success factors (CSFI) towards successful commercialization of the IP products at the centres with beta values of 0.564, $p<0.001$. A similar significant positive relationship exists between the causal link of IP and commercialization procedures and external critical success factors (CSFE) with beta coefficient values of $0.429, p<0.001$. In addition, both CSFI and CSFE have significant impact on communication flow related to IP and commercialization of research products with a beta value of 0.264 and $0.317, p<0.001$ respectively. Furthermore, the path coefficients between policy issues in IP and commercialization of products has shown a significant impact on communication flow and actual commercialization of the intellectual products experienced by respondents with high beta value of 0.256 and 0.343, $p<0.001$ respectively. The same similar positive causal link can be inferred between communication flow and the commercialization of the intellectual products experienced by respondents with a beta value of 0.229, p<0.001. In addition, hypotheses H1, H2, H3, H4, H5, H6 and H7 in the study are supported with an alpha-value less than 0.001 respectively. It is hoped that due attention would be paid to all the recommendation put forward in this study for better enhancement of IP and commercialization of research products at universities.
\end{abstract}

\section{INTRODUCTION}

The growing demand around the world and focus on Intellectual Property (IP) protection and commercialization (IP\&C) lie in the recognition of the IP as another engine of growth for any nation. This is because a nation that relies mainly on its production processes might eventually fizzled out of reach for economy sustainability. This is in line with the law of diminishing returns in sustaining economic growth. To maintain and sustain the economy of a nation, the governments all over the world have invested in innovation activities through sponsoring of research-based model of discovering ideas and valuable intellectual outcome of study from researchers in different disciplines. This can in turn lead into process of innovative economies that is capable of introducing new products and services into the world market. In other words, the focus on innovative economy begins with searching for intellectual property that will progressively and significantly lead to commercialization as the final outcomes of IP discoveries and inventions. The emergence of new information technologies has accelerated the pace of innovation that can help make both discovery of new intellectual properties and their commercialization's possible today. More importantly, the advent of information and communication technologies (ICT) has "facilitated these changes by significantly reducing the costs of outsourcing and cooperation with entities outside the firm. They have fostered greater networking in the economy, speeding the diffusion of knowledge and ideas" (UNECE, 2011). Hence, the contributing values of IP and its commercialization to the economic growth of the nation can be seen through patent portfolio; software 
developed in house; brand name and the distribution chains. There are many interrelated problems associated with IP\&C in any given country of the world except that the contextual problems of one might be different from another. Having said that, it is pertinent to examine the details and procedures and processes underline the commercialization of IPs for their marketability into economic values.

\section{Research Problem}

Today, having known the significant contributions of intellectual property to the economy of the nation, millions of money has been spent on research activities by the government of Malaysia. The government of Malaysia has recognized the needs to support intellectual property and encouraged their commercialization as another engine of economic growth for the country. The procedural processes, communication flow between researchers and the centres for innovation and research for each of the public university is expected to play a critical role in commercializing the intellectual property derived from various government funded research activities. However, the expectation could not meet the reality. There were many cases where huge amount of money was siphoned to research activities and many researchers in their respective expertise came out with new discoveries worthy of patent in the first stage and eventually become intellectual property that can be protected for commercialization.

Successful result from R\&D and innovation plays a key role in advancing Science \&Technology (S\&T) in knowledge-based and innovation driven economy. Under the $10^{\text {th }}$ Malaysian Plan (10MP), the Ministry of Higher Education (MOHE) has introduced Fundamental Research Grant Scheme (FRGS) to promote research activities among universities. Recently, MOHE also announces other research grants like ERGS, LRGS, and PRGS in order to enhance research activities in Malaysia. These grants are awarded for researchers to discover new theories, ideas, and innovations particularly, in cutting edge fields that have been identified by the Malaysian government. In total, the Malaysian government has allocated about RM741 million for R\&D among the universities for the first two years of the 10MP. The budget announced for 2010 has allocated RM 191.5 billion to create an economy based on innovation through Research, Development and Commercialization initiatives at university levels (Nagaretham et al., 2012).

However, only few out of twenty public universities in Malaysia has been successful in commercializing their IP for value of money to support economic performance of the nation. This has raised a lot of eye brows among the policy makers to trace the underline problems with commercialization of the research products. In a preliminary study's report presented to AKEPT by a group of researchers in June 2013, some of the underlined multi-faceted issues such as policy issues, procedures, communication flow and the critical success factors of the roles played by the centres in each selected university had been revealed as key determinants that have direct or indirect relations to successful IP\&C. Given a known fact in policy discuss that such multi-faceted issues in IP\&C are interdependency by their characteristics, the aim of this paper is to synthesize or put these various dimensional issues on a specific framework to model their effects on the IP and Commercialization of the intellectual properties of the research products. At this juncture, the following research questions are raised to address the problems:

1. Do procedures at both centres and agencies for intellectual property and its commercialization (IP\&C) have significant effects on Critical Success Factors (CSFs) of the centre's roles (CSFs whether internal or external)?

2. Do the CSFs have significant effects on communication flow (COMF) related to IP\&C experience?

3. Do policy issues (PI) in procedures have significant effects on COMF related to Intellectual Property and its commercialization (IP\&C) experience?

4. Do both policy issues (PI) and communication flow (COMF) significantly affects the actual commercialization of the research products experienced (CIPE) experience?

\section{Literature Review}

Entrepreneurial university describes the university-level activities towards commercialization of its research products. Such activities can be visualized from both the functions and cohesion of a system in ensuring the internal and external elements that can inhibit or enhance entrepreneurial activity are well observed (Rothaermel et al., 2007). Thus, entrepreneurial interpretation of system viability in relation to university's innovation environment involves the understanding of a number of important concepts. The main concepts that used in this study are procedures, commercialisation experience in dealing with industries, policy issues, and critical success factors (CSFs) of the centre in the management of IP\&C, communication flow and knowledge management of IP\&C. These areas were selected for several reasons. First, the dramatic increase in the commercial use of university's research in the USA which led to the emergence of university technology transfer phenomenon (Yusof and Jain, 2010). Second, the area of technology transfer had received a wider and broader attention covering issues not only related to antecedents and consequences of university technology transfer, commercialization of research through patenting and licensing, and university start-up activities but had 
also been studied from various contexts including the individual context of university technology transfer ranging from the roles of individual agents such as scientists and technology transfer officers, the institutional context which includes science parks and incubators, and, the organizational context which involves organizational design, processes and incentives (Phan and Siegel, 2006). Thirdly, the complexity of the information accentuates contextual factors increases the importance of understanding the key issues behind the breadth of commercialization of intellectual property in Malaysia. As such some of the scholars (Clark, 1998; Röpke, 1998; Etzkowitz, 2003) have expressed the impact of the institutional and organizational context at the university's entrepreneurship level pertinent to success in IP and Commercialization procedures.

\section{Procedures Requirements}

There are a number of procedures required by researchers to undergo before the outcome of their research products known as intellectual properties (IP) can get to the market for economic values. It starts with filing up an application form which could be very simple or complex and varies from one country to another. In this context, Ireland et al., (2006) argued that innovation takes place in organizations in the form of new products, new processes used to create products, and new administrative structures and routines used to help the organizations operate efficiently and effectively. From the innovation perspective, a procedure is classified as viable (procedures viability) if it can react to changes in the environment even though the prospect for commercialization is still too early to anticipate. With prior information on requisite variety, appropriate responses towards the variety of threats and opportunities originating from the environment can be prepared.

The ability of a procedure to respond to its environment is called responsiveness. The higher the variety in a procedural environment, i.e. consulting, contract research, testing, patenting/licensing and others, the higher the need for it to have requisite variety in handling the environment. However, for an environment that has a very high degree of variety, the procedures needs to reduce the number of variety that it can handle, and address it according to its level of existing requisite variety. Recently, Brennan, Wall and McGowan (2005) and Brennan and McGowan (2006) deconstructed the complex phenomenon of academic entrepreneurship into a series of logical categories and conceptual bins that could be further investigated. By synergizing the corporate entrepreneurship perspective with models of organizational knowledge creation, ontological layers and knowledge types, the framework bounded the phenomenon in a way different from the traditional view of entrepreneurship process in relation to the critical success factors which are internal or external to the centres or agencies' environment. Environment refers to elements that are outside of a system which can influence and in turn, be influenced by the system. These elements require coherence with its planned objectives, understanding of the functions and interactions amongst the elements especially in a policy system implementation. The roles and functions of agencies and institutions against the stated objectives of the policy system underpin the chance for IP\&C success. Inconsistencies of a system's objectives with the functions of its supporting agencies can lead to the system's objectives being not fully achievable or its performance might not reach the expected targets (Khairul Akmaliah, 2012). It has been argued that researchers are ready to put up an extra effort to gain more benefits through IP\&C efforts. Thus, aiming to maximize their utility, researchers try to minimize the time input necessary to carry out a transaction instead of a long standing waiting of getting feedback on the commercialization of the research products (IP). Following this rationale, the simplicity of procedures and related expectations regarding these procedures may motivate researchers to choose the IP\&C centre or the Office of Technology Transfer (OTT) to maximize the effort to initiate commercialization or IP, regardless of existing constraints. It is therefore hypothesized that:

H1: Procedures at the centres (CPRO) will positively affect the internal critical success factors (CSFI) of the role played by the centres in IP\&C experience.

$\mathrm{H} 2$ : Procedures at the agencies (APRO) will positively affect the external critical success factors (CSFE) of the role played by the centres in IP\&C experience.

\section{Critical Success Factors (Csfs)}

CSFs also underpin the success of IP\&C initiatives. The critical success factors focused on the role played by the centres and agencies for IP and Commercialization. The CSF function is responsible for detecting challenges and recognizing opportunities in the system's external and internal environment, then communicating this information; which performs the control and policymaking activities respectively. Therefore, the gathering of information from the system's environment enables the system to develop requisite varieties that will allow it to give appropriate responses to its environment. Thus, the CSF function denotes two important dimensions: (a) the gathering of information by the system from and disseminating it back to the environment (i.e., communication flow); and (b) the taking of action by the system based on the information that has been gathered. Vigdor et al., (2007) also professed that critical successful factors are not only determined by a balance between centralization and decentralization in the universities, but also autonomy linked with checks 
and balances in relations to the flow or channel of information about IP\&C. Based on this understanding of critical success factors towards IP\&C activities, at this juncture the following hypotheses are derived:

H3: The internal critical success factors (CSFI) of the roles played by the centres will positively affect the communication flow (COMF) related to IP\&C experience.

H4: The external critical success factors (CSFE) of the roles played by the centres will positively affect the communication flow (COMF) related to IP\&C experience.

\section{Policy Issues}

The policy function provides clarity on the overall direction of the system. It defines the goals and formulates in the running of the system. It also exercises the overall management and control of the system for commercialization (Devine, 2005; Espejo and Gill, 1997). A commercialization system contains a number of subsystems and in turn each of these subsystems must be supported with proper policy. Each of these subsystems has its own complexity and thus each is allocated with variety from its management (the management of the system-in-focus is to allocate to the subsystem its own variety-the subsystem requisite varieties) that will enable the subsystems to give appropriate responses to its respective environment. Therefore, a viable system structure has to be supported by viable policy environment.

In Malaysia, the evolution of Science and Technology has initiated in 1986 through the First National Science and Technology Policy (NSTPI) with the mission of achieving scientific and technological development especially to speed up the economic growth, the industrial development and also to create high-tech (advanced) society (Ahmad and Krisha, 2006). The other factors which lead to lower success rate of commercialization in Malaysia are the implementation of the policies. There are hundreds of policies being introduced in Malaysia to speed up the success rate of commercialization, but then, the policy concerned needs to be backed up by top management's good communication flow. It has been argued that policy issues can bear a profound effect on communication flow of the IP commercialization efforts (Normah, 2011). Each policy being introduced has different ideas and plans which are not interrelated. In another words, there could be a very poor coordination (i.e., communication gap) between the research universities, government and industry due to issues in IP \& commercialization policy itself (Nagaretham et al., 2012). In light of this understanding, thus the hypothesized derived is:

H5: The policy issues associated with procedures will positively affect the communication flow (COMF) related to IP\&C experience.

\section{Communication Flow For Collaboration And Commercialization}

The communication flow function is related to the respective management units and/or operating units within each subsystem. The collaboration between academics of either within or cross faculties or even public institutions of higher learning (IHL) in terms of research and other scholarly activities is more common than their counterparts in the private IHLs. As a matter of fact, the Ministry of Higher Education (MOHE) has been stressing on collaboration in performing scholarly activities through effective communication flow from those with commercialization experience.

One of the examples noted is the inclusion on the Ministry's website on directory of expertise of all the professors and academic staff throughout the public IHLs in the country (see www.mohe.gov.my). Such an initiative would have attracted many researchers in the same field to work together on some research projects that have the potential to be funded by various government agencies. In contrast, the low score for communication flow in private Higher Education Institutions (HEIs) is due to the priority given to activities that facilitate the maximization of profits for the HEIs, such as teaching, which is largely an individual effort, research and other activities that require collaboration and funding. This function collects information directly from the operating units, which are to be fed directly to the control function, and in turn disseminates relevant information back, from the controlling function, directly to the operating units, without having to go through their management function. Its responsibility is to examine the performance of the operating units against their expected outcomes. The relationships between the monitoring function and the operating units can be formal or informal but they are not based on authority (Normah, 2011; Nagaretham et al., 2012). Communication flow helps in knowledge management of the IP\&C in the university and also keeps in pace the dynamic growth as well as expansion of that knowledge for future researchers in the area. The function of knowledge in IP\&C at the university is directly related to each of the management units. This function helps to generate synergy among the operating units. Tools used to create the synergy include coordination via legal systems as well as through a good communication norm (Devine, 2005). Moreover, coordination among the operating functions also serves the purpose of ensuring their activities are not in direct conflict with each other, and their functions 
are not redundant to each other. This way, a highly-coordinated operation can be achieved, thus, reducing the need for greater control by management (Espejo and Gill, 1997).

According to Ireland et al., (2006), innovation or bringing something new into being, is one of the most vital uses of shared organizational knowledge via a good communication flow, which can affect commercialization experience and efforts of the researchers. The operating units are monitored by a management unit, indicated by the two arrow lines between the operating units and their management units, which are lines of formal authority. The operating units are directly linked, back and forth to their own respective environmental elements. The lines that connect the units to the elements signify interactions between them and the environment (e.g. customers). However, previous applications of VSM on policy systems mainly focused on describing the entire economy system, for example, in the Cybersyn project in Beer (1981), or the innovation system of a country, for example New Zealand in Devine (2005), or in diagnosing industry structures. Less focus is given to the academic members and graduates to engage in entrepreneurial behavior, using knowledge as a foundation for continuous and successful innovations as they do so due to communication gaps (Martinelli, 2008). As Yusof and Jain (2012) summed up, the "entrepreneurial process and actions" covers the university-setting via effective communication of feedback (Röpke,1998; Kirby, 2006; Etzkowitz, 2003) which leads not only to new venture creation (Chrisman et al., 1995; Etzkowitz, 2003) and other sources of income (Etzkowitz, 1983) but also to technology transfer activities which include commercialization experience and commoditization (Jacob et al. 2003) through university-government-industry collaboration (Röpke, 1998; Subotzky, 1999) and supported by the acquisition of external funding (Subotzky, 1999). Innovativeness is mainly achieved through the act of entrepreneurial engagement with good communication flow. Thus, it refers to the ability of a university's business entrepreneurs to recognize new opportunities and exploit them to produce products/services that benefit customers while bringing in profits. In this perspective, $R \& D$ is regarded as the core source of innovation commercialization. The resulting innovation from this capability is enabled by entrepreneurial adaptation in higher education and connected the university structure of information flow and environmental forces with management, governance and leadership that can affect commercialization experienced by researchers (Sporn, 2001). Thus, innovation from university researchers resulted into a commercialized product does not only benefit the consumers and businesses, but also the society at large (Khairul Akmaliah and Mohd Fuaad, 2008; Martin, 1994; Shane and Venkataraman, 2000; Sundbo, 1998).

Building on an effective knowledge management mechanism is critical in which the activities of producing goods and services (innovation and entrepreneurship) determining profitability of the resulting innovation. As a major hindrance to capacity to innovate, the cultural problem is in fact considered a major challenge in change management initiatives among the Higher Education Institutes (HEIs) because many faculty members consider knowledge as proprietary and something that is not shared freely (Wind and Main, 1999). Detert et al. (2000) thereby rightfully remarked that an organisation's prevailing culture can sabotage management efforts of IP\&C before they can even begin. Their view, which is called the innovation system perspective, suggests the importance of related institutions, government policies, and locations as the foundation toward achieving a more efficient innovation system. More recently, partnering between public and private sector is one of the efforts taken to commercialize research products successfully. The public sectors consist of research institutions, universities and tertiary institutions are expected to collaborate with private sectors mainly from multinational firms to speed up commercialization experience. The idea of it is to translate the practical into innovative products, service and application by the public institutions via effective communication channels and this will be strongly influenced by the private sector into commercialization market but this can seriously be affected by policy issues within the communication flow itself (Nagaretham et al., 2012). Accordingly, any environmental elements that influence an organization's innovation process and those of their cohesion are to be understood and well managed. At this juncture again, the following hypotheses are hypothesized:

H6: The communication flow (COMF) related to IP\&C between researchers, centres and the agencies will positively affect the actual commercialization experience (CIPE).

H7: The policy issues associated with procedures will positively affect the actual commercialization experience (CIPE).

Based on the literatures related to IP and its commercialization issues, a model that could help tie the discussed issues together is proposed for this study. In addition, the preliminary earlier data from interviews of some experienced respondents in Malaysian IP and Commercialization have testified to the proposed model of the study as shown in Figure 1. However, it needs to be tested with a strong computational and rigorous analysis to see the pattern of relationships amongst them. 


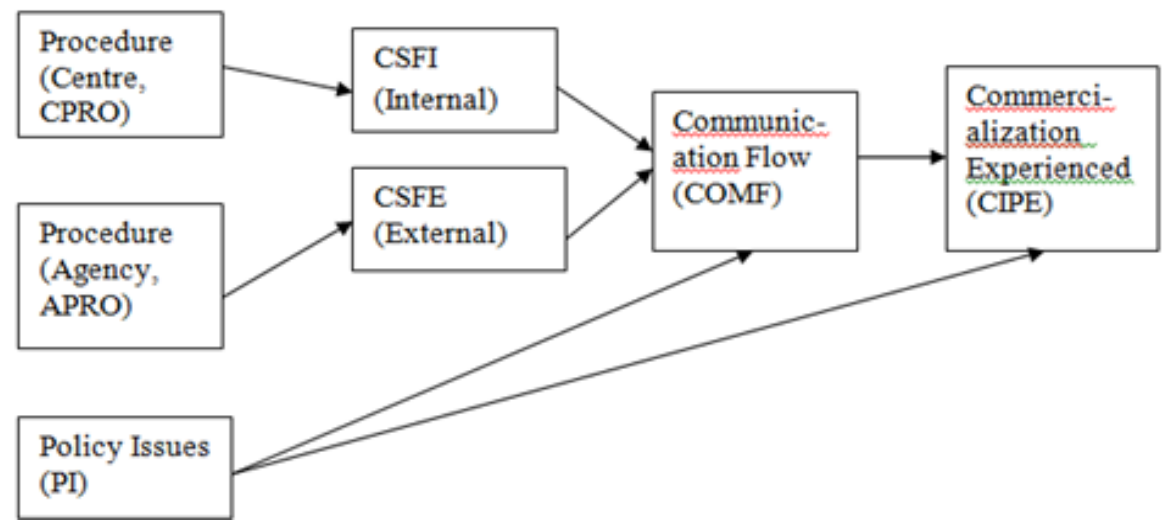

Figure 1: A Model of Key Determinant Issues for an Effective IP \& Commercialization Experience

\section{Data Collection And Methodological Approach}

Data collection was done through the design of a survey questionnaire. Information was collected over a period between March and April 2013 at one shot. Hence, it is a cross-sectional design method. The respondents were the researchers that have at least attempted to patent and/or commercialize their research products through the help established centres in each selected government owned universities in Malaysia. The nature of data collection was through a five-point Likert survey questionnaire. A total of 150 questionnaires were distributed to them but the authors only managed to collect back 134 valid questionnaires for further analyses.

1. Goodness of Measures for Instrumentation

The questionnaire used consists of a five-point Likert scale to acquire information for each of the construct dimension in the model of the study (Figure 1). Based on the insights obtained from previous study, a questionnaire was developed to earn information. In this study, both validity and reliability tests to measure the accuracy of the data were used. Construct validity was used to test how well the instrument developed measures a particular construct (Sekaran \& Bougie, 2010), while reliability was used to test how consistently the measuring instruments have measured the constructs. Validity measures in this research were in three folds in terms of construct, convergent and discriminant in order to examine how well the questionnaires used could tap the constructs as theorized in the model.

2. Assessing the Inner and Outer Parts of the Model's Constructs

Fig 2 of the model displays the outer and inner parts of the model's constructs. This is necessary to confirm the structural links between the variables in the model and the loading of each items used to measure respective variables.

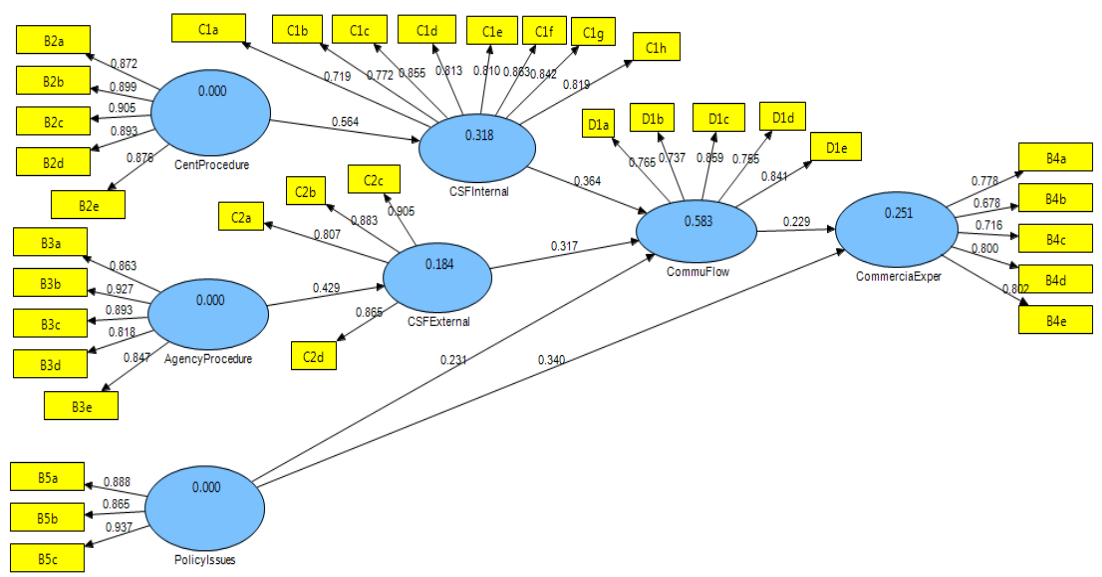

Figure 2: Inner and Outer Values of the Model 
An observation showed that the items of each variable really reflect their respective construct which are intended to measure. The structural links among the variables of interests in the model have yielded positive relations among each others as expected and predicted. However, there is a need to further test the significance of the relationships among them in another section of this paper to establish the predicted hypotheses. This is because structural values of the inner model cannot be taken as a proof of the hypotheses until bootstrapping for the test of significance is carried out for confirmation. In addition, there is a need to examine factorial analysis of the constructs in relation to the items used to measure them. This can be explained through rigorous diagnostic of validity of the model with respect to items-relation among all the constructs, which include construct validity diagnostic, discriminant analysis, convergent and divergent validity as well as the measurement model at large.

\subsection{Construct Validity}

Construct validity is assessed by looking at loadings and cross loadings to identify if there any problematic items. Following Hair et al. (2010), a significant value of 0.5 loadings is used as a cut-off. As has been depicted in Table 1, items measuring each construct in the study are highly loaded on their particular construct and loaded lower on others indicating that construct validity of the instrument is established.

Table 1: Loadings and Cross Loadings for Construct Validity

\begin{tabular}{|c|c|c|c|c|c|c|c|}
\hline Items & $\begin{array}{l}\text { Centre } \\
\text { Procedure } \\
\text { (CPRO) }\end{array}$ & $\begin{array}{l}\text { Agent } \\
\text { Procedure } \\
\text { (APRO) }\end{array}$ & $\begin{array}{l}\text { Policy } \\
\text { Issue (PI) }\end{array}$ & $\begin{array}{l}\text { Internal } \\
\text { Critical } \\
\text { Success } \\
\text { Factor } \\
\text { (CSFI) }\end{array}$ & $\begin{array}{l}\text { External } \\
\text { Critical } \\
\text { Success } \\
\text { Factor } \\
\text { (CSFE) } \\
\end{array}$ & $\begin{array}{l}\text { Communic } \\
\text { ation Flow } \\
\text { (COMF) }\end{array}$ & $\begin{array}{l}\text { Commercializ } \\
\text { ation of IP } \\
\text { Experienced } \\
\text { (CIPE) }\end{array}$ \\
\hline CPRO 1 & 0.8717 & 0.4947 & 0.2271 & 0.2637 & 0.2238 & 0.1412 & 0.3212 \\
\hline CPRO 2 & 0.8995 & 0.3979 & 0.3528 & 0.3060 & 0.4936 & 0.3170 & 0.2172 \\
\hline CPRO 3 & 0.9046 & 0.2387 & 0.3105 & 0.3122 & 0.3904 & 0.1534 & 0.2334 \\
\hline CPRO 4 & 0.8930 & 0.2654 & 0.2477 & 0.4323 & 0.2757 & 0.2385 & 0.1354 \\
\hline CPRO 5 & 0.8756 & 0.3265 & 0.3966 & 0.3714 & 0.3833 & 0.1346 & 0.2342 \\
\hline APRO1 & 0.3996 & 0.8632 & 0.4807 & 0.4430 & 0.3822 & 0.2112 & 0.1142 \\
\hline APRO 2 & 0.4117 & 0.9266 & 0.3000 & 0.2472 & 0.2759 & 0.1379 & 0.2372 \\
\hline APRO3 & 0.2695 & 0.8933 & 0.2760 & 0.4550 & 0.2518 & 0.1248 & 0.2341 \\
\hline APRO4 & 0.2004 & 0.8181 & 0.4004 & 0.3875 & 0.3254 & 0.2368 & 0.1332 \\
\hline APRO5 & 0.3365 & 0.8474 & 0.3736 & 0.2233 & 0.2593 & 0.1152 & 0.2251 \\
\hline PI_1 & 0.4585 & 0.4585 & 0.8884 & 0.2301 & 0.3016 & 0.2136 & 0.2433 \\
\hline PI_2 & 0.3996 & 0.2379 & 0.8651 & 0.3475 & 0.2799 & 0.2207 & 0.3107 \\
\hline PI3_3 & 0.3523 & 0.4848 & 0.9375 & 0.3429 & 0.3911 & 0.3158 & 0.2123 \\
\hline CSFI_1 & 0.4029 & 0.2568 & 0.2412 & 0.7189 & 0.2458 & 0.2967 & 0.2411 \\
\hline CSFI_2 & 0.3117 & 0.3516 & 0.2170 & 0.7716 & 0.2385 & 0.1372 & 0.2271 \\
\hline CSFI_3 & 0.2304 & 0.2536 & 0.1434 & 0.8545 & 0.3393 & 0.3196 & 0.2120 \\
\hline CSFI_4 & 0.2662 & 0.3208 & 0.2385 & 0.8127 & 0.4555 & 0.2279 & 0.1122 \\
\hline CSFI_5 & 0.4268 & 0.3558 & 0.3346 & 0.8097 & 0.3824 & 0.2547 & 0.1247 \\
\hline CSFI_6 & 0.3557 & 0.2967 & 0.1805 & 0.8633 & 0.3155 & 0.1300 & 0.2200 \\
\hline CSFI_7 & 0.2087 & 0.4971 & 0.0545 & 0.8423 & 0.2374 & 0.2163 & 0.3162 \\
\hline CSFI_8 & 0.4823 & 0.3596 & 0.2400 & 0.8194 & 0.3556 & 0.1268 & 0.2268 \\
\hline CSFE1 & 0.3669 & 0.2241 & 0.3637 & 0.1234 & 0.8068 & 0.3557 & 0.2457 \\
\hline CSFE2 & 0.2116 & 0.3298 & 02402 & 0.2139 & 0.8835 & 0.2187 & 0.3122 \\
\hline CSFE3 & 0.4218 & 0.4415 & 0.3283 & 0.3885 & 0.9046 & 0.2123 & 0.1123 \\
\hline CSFE4 & 0.3218 & 0.3415 & 0.2284 & 0.2885 & 0.8654 & 0.3169 & 0.3132 \\
\hline COMF1 & 0.4334 & 0.4446 & 0.3782 & 0.2898 & 0.1653 & 0.7649 & 0.2141 \\
\hline COM2 & 0.2302 & 0.3148 & 0.2359 & 0.3926 & 0.2274 & 0.7371 & 0.1370 \\
\hline COMF3 & 0.3418 & 0.2854 & 0.3134 & 0.3604 & 0.1721 & 0.8589 & 0.2189 \\
\hline COMF4 & 0.2434 & 0.2141 & 0.3173 & 0.2300 & 0.1257 & 0.7551 & 0.2250 \\
\hline COMF5 & 0.2324 & 0.1279 & 0.2284 & 0.2332 & 0.2833 & 0.8409 & 0.1408 \\
\hline CIPE1 & 0.1345 & 0.2322 & 0.3150 & 0.2268 & 0.3122 & 0.2523 & 0.7783 \\
\hline CIPE2 & 0.1204 & 0.2302 & 0.2174 & 0.3557 & 0.2258 & 0.2372 & 0.6777 \\
\hline CIPE3 & 0.1545 & 0.3142 & 0.2112 & 0.2087 & 0.1518 & 0.1232 & 0.7164 \\
\hline CIPE4 & 0.2402 & 0.1234 & 0.2237 & 0.2123 & 0.3254 & 0.1521 & 0.8003 \\
\hline CIPE5 & 0.2637 & 0.2257 & 0.2454 & 0.3129 & 0.2193 & 0.2216 & 0.8016 \\
\hline
\end{tabular}




\subsection{Convergent Validity}

The convergent validity of the instrument was also tested to examine the multiple items measuring the same construct of the study and the degree of their agreement with one another. In this respect, the factor loadings alongside both composite reliability and average variance were extracted for proper examination.

Table 2: Loadings, Composite Reliability and Average Variance Extracted

\begin{tabular}{|c|c|c|c|}
\hline Measuring Items & Loadings & $\begin{array}{l}\text { Composite } \\
\text { Reliability } \\
(\text { CR })^{\mathrm{a}}\end{array}$ & 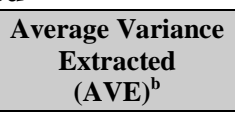 \\
\hline B2a $<-$ CPRO 1 & 0.871759 & \multirow{5}{*}{0.949590} & \multirow{5}{*}{0.790281} \\
\hline $\mathrm{B} 2 \mathrm{~b}<-\mathrm{CPRO} 2$ & 0.899451 & & \\
\hline $\mathrm{B} 2 \mathrm{c}<-\mathrm{CPRO} 3$ & 0.904633 & & \\
\hline $\mathrm{B} 2 \mathrm{~d}<-\mathrm{CPRO} 4$ & 0.893007 & & \\
\hline B2e $<-$ CPRO 5 & 0.875559 & & \\
\hline B3a $<-$ APRO1 & 0.863214 & \multirow{5}{*}{0.939812} & \multirow{5}{*}{0.757794} \\
\hline $\mathrm{B} 3 \mathrm{~b}<-\mathrm{APRO} 2$ & 0.926611 & & \\
\hline $\mathrm{B} 3 \mathrm{c}<-\mathrm{APRO} 3$ & 0.893273 & & \\
\hline B3d <- APRO4 & 0.818052 & & \\
\hline B3e $<-$ APRO5 & 0.847395 & & \\
\hline B5a $<-$ PI_1 & 0.888413 & \multirow{3}{*}{0.925419} & \multirow{3}{*}{0.805475} \\
\hline B5b $<-$ PI_2 & 0.865056 & & \\
\hline B5c $<-$ PI_3 & 0.937458 & & \\
\hline Cla $<-$ CSFI_1 & 0.718999 & \multirow{8}{*}{0.93949} & \multirow{8}{*}{0.660621} \\
\hline Clb $<-$ CSFI_2 & 0.771582 & & \\
\hline Clc $<-$ CSFI_3 & 0.854525 & & \\
\hline Cld <-CSFI_4 & 0.812734 & & \\
\hline Cle $<-$ CSFI_5 & 0.80975 & & \\
\hline Clf $<-$ CSFI_6 6 & 0.863334 & & \\
\hline Clg $<-$ CSFI_7 & 0.842269 & & \\
\hline Clh $<-$ CSFI_8 & 0.819426 & & \\
\hline $\mathrm{C} 2 \mathrm{a}<-$ CSFE1 & 0.806784 & \multirow{4}{*}{0.922828} & \multirow{4}{*}{0.749674} \\
\hline $\mathrm{C} 2 \mathrm{~b}<-\mathrm{CSFE} 2$ & 0.883481 & & \\
\hline $\mathrm{C} 2 \mathrm{c}<-\mathrm{CSFE} 3$ & 0.904635 & & \\
\hline C2d <-CSFE4 & 0.865387 & & \\
\hline D1a <-COMF1 & 0.764890 & \multirow{5}{*}{0.893982} & \multirow{5}{*}{0.628656} \\
\hline $\mathrm{D} 1 \mathrm{~b}<-\mathrm{COM} 2$ & 0.737075 & & \\
\hline D1c <- COMF3 & 0.858927 & & \\
\hline D1d <-COMF4 & 0.755070 & & \\
\hline D1e $<-$ COMF5 & 0.840868 & & \\
\hline B4a $<-$ CIPE1 & 0.778257 & \multirow{5}{*}{0.869462} & \multirow{5}{*}{0.572254} \\
\hline B $4 b<-$ CIPE2 & 0.677739 & & \\
\hline B4c <-CIPE3 & 0.716433 & & \\
\hline B4d <- CIPE4 & 0.800310 & & \\
\hline B4e $<-$ CIPE 5 & 0.801560 & & \\
\hline
\end{tabular}

${ }^{* * *} p<0.001,(C R) a:$ Composite reliability $(\rho c)=\left(\sum \lambda i\right) 2 /[(\Sigma \lambda i) 2+\Sigma$ Var $(\varepsilon i)]$, where $\lambda i$ is the outer factor loading, and $\operatorname{Var}(\varepsilon i)=1-\lambda i$. is the measurement error or the error variance associated with the individual indicator variable(s) for that given factor (see: Fornell \& Larcker, 1981).

$(A V E) b:$ Average Variance Extracted $(A V E)=(\Sigma \lambda 2 i) /[(\Sigma \lambda 2 i)+\Sigma \operatorname{Var}(\varepsilon i)]$, where $\lambda i$ is the outer factor loading, and $\operatorname{Var}(\varepsilon i)=1-\lambda i$, is the measurement error or the error variance associated with the individual indicator variable(s) for that given factor (see: Fornell \& Larcker, 1981).

The results in Table 2 showed that all items' loadings exceeded the recommended value of 0.5 as suggested by Hair et al. (2010). In addition, the composite reliability was used to test how far the construct indicators really represent the latent and the values obtained ranging from 0.9496 to 0.8695 , which exceeded the recommended value of 0.7 by Hair et al. (2010). The average variance extracted (AVE) was used to relatively examine the variance captured by the construct indicators to measurement error. According to Barclay et al. (1995), the value must be above 0.5 for appropriation and justification. In this study, the AVEs for the indicators are within the range of 0.5723 and 0.8055 with respect to each dimension of the measurement constructs. 
Looking at the results for the parameter estimates the test of their statistical significance ( $t$-values at $p<0.001$ alpha levels) which can be concluded that all the variables in the model are valid measures of their respective constructs (Chow \& Chan, 2008).

\subsection{Discriminant Validity}

The discriminant validity of the measures has equally been tested to examine the degree to which items differentiate among constructs. This is carried out first by looking at correlations between the measures for possible potential overlapping of constructs. Second, whether the average variance shared between each construct and what it measures are greater than the average variance shared with other constructs are also explored, as suggested by Compeau et al. (1999).

In this respect, the results as in Table 3 showed that the squared correlations for each construct is less than the average squared root of the variance extracted by the indicators measuring a particular construct. Hence, the measurement model reflects an adequate convergent validity and discriminant validity respectively.

Table 3: Discriminant Result for Latent Variable Correlations

\begin{tabular}{|c|c|c|c|c|c|c|c|}
\hline $\begin{array}{c}\text { Model's } \\
\text { Constructs }\end{array}$ & CPRO & APRO & PI & CSFI & CSFE & COMF & CIPE \\
\hline CPRO & $\mathbf{0 . 8 8 8 9}$ & & & & & & \\
\hline APRO & 0.4401 & $\mathbf{0 . 8 7 0 5}$ & & & & & \\
\hline PI & 0.2892 & 0.2060 & $\mathbf{0 . 8 9 7 5}$ & & & & \\
\hline CSFI & 0.3179 & 0.2940 & 0.2101 & $\mathbf{0 . 8 1 2 8}$ & & & \\
\hline CSFE & 0.2256 & 0.1837 & 0.2009 & 0.4458 & $\mathbf{0 . 8 6 5 8}$ & & \\
\hline COMF & 0.4520 & 0.2790 & 0.2919 & 0.4643 & 0.4405 & $\mathbf{0 . 7 9 2 8}$ & \\
\hline CIPE & 0.0869 & 0.0916 & 0.2144 & 0.0982 & 0.0856 & 0.1697 & $\mathbf{0 . 7 5 6 5}$ \\
\hline
\end{tabular}

\subsection{Reliability Analysis}

Reliability is an indication of the internal consistency of the instruments measuring the concepts and helps access the "goodness" of measure (Sekaran \& Bougie, 2010). There are many different types of reliability estimates (Ambali, 2009). One of the most widely used tests is Cronbach's Alpha that is employed in this study as shown in Table 4. By looking at the results of the Cronbach's Alpha range from 0.8284 to 0.9259, thus confirms the reliability of the instrument used. It is worth mentioning that the range of reliability test using Cronbach's Alpha ranges from zero to one. The closer the value to one, the higher the level of internal consistency among items and thus the reliability of the instruments are ensured in this study.

Table 4: Reliability Tests Result

\begin{tabular}{|c|c|c|}
\hline Variable & No. of Items & Cronbach's Alpha \\
\hline CPRO & 5 & 0.887946 \\
\hline APRO & 5 & 0.920123 \\
\hline PI & 3 & 0.896425 \\
\hline CSFI & 8 & 0.925986 \\
\hline CSFE & 4 & 0.877946 \\
\hline COMF & 5 & 0.851824 \\
\hline CIPE & 5 & 0.828441 \\
\hline
\end{tabular}

The fact that the nature of the data is a self-reported Harman's one-factor test, it was examined to address any potential common method variance bias that may likely to exist. As contended by Podsakoff \& Organ (1986), common variance bias is problematic if a single latent factor accounts for the majority of the total explained variance. In this study, the result of the un-rotated factor analysis shows that the first factor only accounted for $13.3 \%$ of the total $75.37 \%$ variance and thus the common method bias is not a problem in the study.

\section{Findings Of The Study \& Discussions}

According to Table 5, majority of the participants are males with $59 \%$ as compared to $40 \%$ of females. Interestingly, their age ranged from 24-26 years to 36 years and above, which sounds a sense of maturity in engaging with commercialization of intellectual property (IP) of research products. However, even though they have longer years of experience or engagement in commercialization of IP does not really mean that they have 
been accomplishing their respective objectives of commercialization. In addition, researchers in this study have different ethnic backgrounds. Majority of them are Malay with 56\% followed by Chinese (24.6\%). The rest are Indian and other nationals and/or ethnic origins with $7.5 \%$ and $10.4 \%$ respectively. The data as tabulated in Table 5 also showed that the majority of the participants involved in commercialization of intellectual property are local researchers with $86.6 \%$ and the rest are international experts from different fields and disciplines.

Majority of the researchers participated in this study are from the science and technology disciplines such as engineering (40\%), medical science (35.1\%) and computer science $(9.7 \%)$. The rest of respondents are from education (6\%), art and design $(0.7 \%)$ and a minimal degree of other social sciences (3\%) respectively. Most of the respondents are $\mathrm{PhD}$ holders $(77.6 \%)$, which indicate their licence to get really involved in dynamic and progressive research activities for human enhancement and improvements.

Table 5: Profile of Respondents

\begin{tabular}{|c|c|c|}
\hline Variables & Frequency & Percentage \\
\hline \multicolumn{3}{|l|}{ Gender } \\
\hline Male & 79 & $59 \%$ \\
\hline Female & 54 & $40 \%$ \\
\hline Missing System & 1 & $1 \%$ \\
\hline \multicolumn{3}{|l|}{ Age } \\
\hline $24-26$ & 5 & $3.7 \%$ \\
\hline $27-29$ & 7 & $5.2 \%$ \\
\hline $30-32$ & 12 & $09 \%$ \\
\hline $33-35$ & 15 & $11.2 \%$ \\
\hline 36 and above & 95 & $70.9 \%$ \\
\hline \multicolumn{3}{|l|}{ Ethnic Group } \\
\hline Malay & 75 & $56 \%$ \\
\hline Chinese & 33 & $24.6 \%$ \\
\hline Indian & 10 & $7.5 \%$ \\
\hline Others & 14 & $10.4 \%$ \\
\hline \multicolumn{3}{|l|}{ Origin } \\
\hline Local & 116 & $86.6 \%$ \\
\hline International & 18 & $13.4 \%$ \\
\hline \multicolumn{3}{|l|}{ Qualification } \\
\hline PhD. & 104 & $77.6 \%$ \\
\hline MA & 21 & $15.7 \%$ \\
\hline BA & 8 & $6.0 \%$ \\
\hline Professional & 1 & $0.7 \%$ \\
\hline \multicolumn{3}{|l|}{ Faculty } \\
\hline Engineering & 54 & $40.3 \%$ \\
\hline Medical/Science & 47 & $35.1 \%$ \\
\hline Education & 8 & $6.0 \%$ \\
\hline Computer Science & 13 & $9.7 \%$ \\
\hline Agriculture & 2 & $1.4 \%$ \\
\hline Food Technology & 4 & $3.0 \%$ \\
\hline Dentistry & 1 & $0.7 \%$ \\
\hline Art and Design & 1 & $0.7 \%$ \\
\hline Others/Social Science & 4 & $3.0 \%$ \\
\hline \multicolumn{3}{|l|}{ Year Involved in Commercialization } \\
\hline $1-5$ years & 93 & $69.4 \%$ \\
\hline $6-11$ years & 33 & $24.6 \%$ \\
\hline $12-17$ years & 6 & $4.5 \%$ \\
\hline 18 years and above & 2 & $1.5 \%$ \\
\hline \multirow{2}{*}{\multicolumn{3}{|c|}{$\begin{array}{l}\text { Status of Intellectual Property (IP) / Commercialized Product } \\
\text { patent filing/pending }\end{array}$}} \\
\hline & & \\
\hline commercialized & 11 & 8.2 \\
\hline potential product/model/prototype & 11 & 8.2 \\
\hline Other IPs & 16 & 11.9 \\
\hline Patent and commercialized & 4 & 3.0 \\
\hline \multirow{2}{*}{ Unknown } & 3 & 2.2 \\
\hline & 28 & 20.9 \\
\hline
\end{tabular}

The respondents have varying degree of years of involvement in commercializing their products ranging from filling up applications, downloading related files to monitoring the feedback and/or approval. Majority of them have at least 1-5 years (69.4\%) followed by 6-11 years (24.6\%) involvement in commercialization. On a separate note, it is interesting to mention that about 5 percent of the researchers have been involving in commercialization of their intellectual properties for those in category of 12-17 years experience. In terms of actual commercialization of IP status, majority (45.5\%) of respondents asserted that they are still at patent/filing pending stage. Only very little (8.8\%) among the researchers have made their ways to the commercialized stage. While minimal percentage $(8.8 \%)$ has been granted patent certificate, the findings 
reflected that certain percentage of about $21 \%$ among the participated researchers have no idea about the status of their registered IP or the commercial viability of their products. Evidently as in Table 5, only $2.2 \%$ of the total respondents were able to successfully commercialize their research products and reach the market for value of money.

\section{Descriptive Analysis}

\section{General Satisfaction with Procedures in IP and Commercialization}

According to Table 6 the results showed that only $47 \%$ of the respondents are satisfied with the procedures for filling up application forms in IP and Commercialization processes. It appears that the satisfactory level is still below average of 50\%. The results in Table 6 also indicated that the percentage level of satisfaction for dealing with the relevant agencies as well as industries are below average, that is, $30 \%$ and $35.1 \%$ respectively.

Table 6: General Satisfaction Level with Procedures in IP \& Commercialization Process

\begin{tabular}{|l|c|c|c|c|}
\hline \multicolumn{1}{|c|}{ Satisfaction Level } & $\begin{array}{c}\text { Filling up the forms at } \\
\text { Centre } \\
(\boldsymbol{\%})\end{array}$ & $\begin{array}{c}\text { Dealing with the } \\
\text { relevant agencies } \\
(\boldsymbol{\%})\end{array}$ & $\begin{array}{c}\text { Dealing with the } \\
\text { industries } \\
(\boldsymbol{\%})\end{array}$ & $\begin{array}{c}\text { Dealing with the } \\
\text { Bursar } \\
(\mathbf{\%})\end{array}$ \\
\hline Very unsatisfied & 1.5 & 2.2 & 4.5 & 6.7 \\
\hline Unsatisfied & 7.5 & 12.7 & 14.2 & \\
\hline Neutral & 34.3 & 48.5 & 44.0 & \\
\hline Satisfied & 47.0 & 30.6 & 35.1 & 54.5 \\
\hline Very satisfied & 9.7 & 6.0 & 2.2 & 24.6 \\
\hline
\end{tabular}

The same goes to the procedures in dealing with bursar with only $24.6 \%$ level of satisfaction. According to the results in Figure 3, the overall total satisfaction level of the respondents is considered to be extremely low $(36.6 \%)$. Only a minimal number $(3.7 \%)$ of respondents indicated that they were very satisfied with the overall procedures in IP and Commercialization processes. However, a vast majority of the respondents still have mixed-feelings about the general procedures in IP and Commercialization of their research products.

\section{Satisfaction with Procedures at the Level of the Centres}

A critical examination of the results in Table 7 showed that while $41.8 \%$ and $38.8 \%$ of the respondents were satisfied with transparency and feedback on procedures respectively, only $11.2 \%$ and $10.4 \%$ respectively indicated that they were very satisfied. However, this percentage number of respondents is extremely low. The same goes to the issues on the time taken to complete each stage of the IP and Commercialization processes at the university's centres. Overall, the highest percentage of the respondents who viewed the procedures at the centres is $44 \%$ at the satisfied level and those who were very satisfied were just a marginal percentage of the respondents (i.e. 8.2\%). From the results, it is very obvious that the satisfactory level of respondents with respect to procedures and processes in IP and Commercialization is below the normal average of 50\%, one would expect at least.

\section{Satisfaction with Procedures at the Level of the Agencies}

The results in Table 8 shows that while $38.8 \%$ and $30.6 \%$ of the respondents were satisfied with transparency and feedback on procedures respectively, only $3.7 \%$ indicated that they were very satisfied at the agency level. However, this percentage of respondents can be considered very low as compared to those that were not satisfied and/or neutral. The same goes to the issues of time taken to complete each stage of the IP and Commercialization processes at the agency levels.

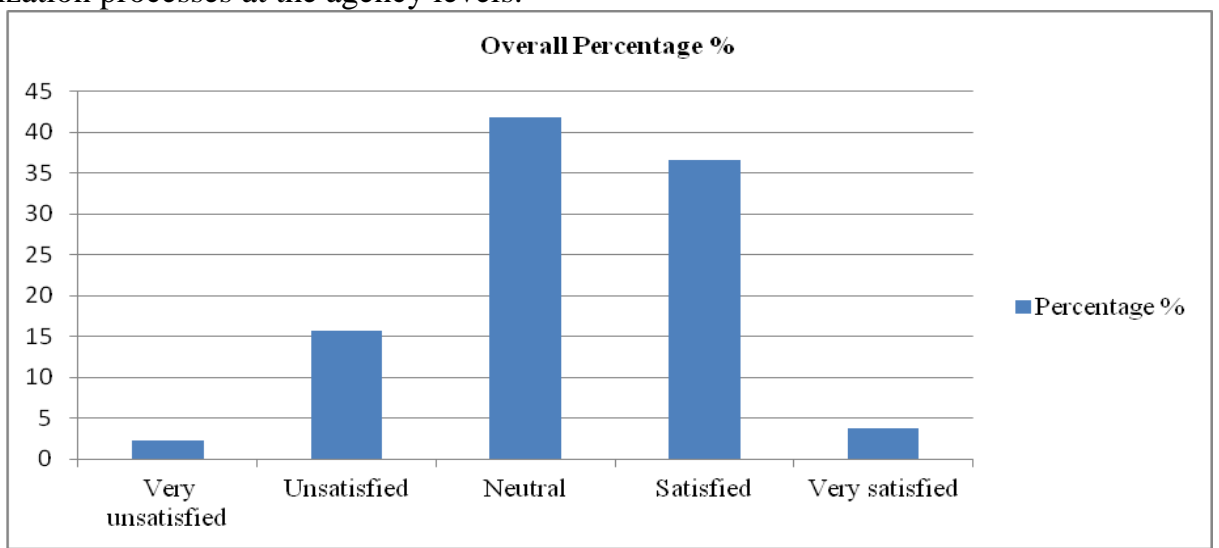

Figure 3: Overall Level of Satisfaction with Procedures 
Table 7: Satisfaction with IP \& Commercialization Procedures at the Level of the Centres

\begin{tabular}{|l|c|c|c|c|}
\hline \multicolumn{1}{|c|}{ Satisfaction Level } & $\begin{array}{c}\text { Transparency of } \\
\text { procedures (\%) }\end{array}$ & $\begin{array}{c}\text { Feedback on } \\
\text { procedures } \\
(\boldsymbol{\%})\end{array}$ & $\begin{array}{c}\text { Time taken to complete } \\
\text { each stage of the } \\
\text { process } \\
(\boldsymbol{\%})\end{array}$ & $\begin{array}{c}\text { Simplicity of the } \\
\text { procedures at } \\
\text { Centers } \\
(\boldsymbol{\%})\end{array}$ \\
\hline Very unsatisfied & 2.2 & 3.0 & 7.5 & 2.2 \\
\hline Unsatisfied & 6.7 & 9.0 & 16.4 & 9.7 \\
\hline Neutral & 38.1 & 38.8 & 32.1 & 35.8 \\
\hline Satisfied & 41.8 & 38.8 & 35.8 & 44.0 \\
\hline Very satisfied & 11.2 & 10.4 & 8.2 & 8.2 \\
\hline
\end{tabular}

Overall, the categories of the respondents who were satisfied with general simplicity of the processes and procedures at the agencies are just $43.3 \%$ and those who were very satisfied were just a marginal percentage of the respondents (i.e. 4.5\%). From the results, it is very obvious that the satisfactory level of respondents with respect to procedures and general processes in IP and Commercialization is lower as compared to a normal average of 50\% that one would likely to expect. In other words, most of the respondents have mixed-feelings of satisfaction level with the procedures at the agency level ranging from time taken to transparency of procedures respectively (ranging from $41 \%$ to $44.8 \%$ ).

Table 8: Satisfaction with IP \& Commercialization Procedures at the Level of the Agencies

\begin{tabular}{|l|c|c|c|c|}
\hline \multicolumn{1}{|c|}{ Satisfaction Level } & $\begin{array}{c}\text { Transparency of } \\
\text { procedures (\%) }\end{array}$ & $\begin{array}{c}\text { Feedback on } \\
\text { procedures } \\
\mathbf{( \% )}\end{array}$ & $\begin{array}{c}\text { Time taken to } \\
\text { complete each stage of } \\
\text { the process } \\
(\boldsymbol{\%})\end{array}$ & $\begin{array}{c}\text { Simplicity of the } \\
\text { procedures at } \\
\text { Centers } \\
(\boldsymbol{\%})\end{array}$ \\
\hline Very unsatisfied & & 4.5 & 7.5 & 2.2 \\
\hline Unsatisfied & 3.0 & 13.4 & 18.7 & \\
\hline Neutral & 10.4 & 47.8 & 41.0 & \\
\hline Satisfied & 44.8 & 30.6 & 29.9 & \\
\hline Very satisfied & 38.1 & 3.7 & 3.0 & 3.3 \\
\hline
\end{tabular}

Satisfaction with IP and Commercialization Policy at both Centre and Agency

There are three significant related issues to IP and Commercialization policies, which among other things, were examined in this study. First, the level of respondents with the issue of financial terms stipulated in the IP and Commercialization documents was examined and the percentage of those who are satisfied and/or very satisfied with it is very low $(26.9 \%, 3.7 \%$ respectively) as in Table 9 . The same goes to the perception on the policy helping towards commercialization of research products with only a minimal percentage of respondents were very satisfied $(4.5 \%)$ and $32.8 \%$ indicated their satisfaction. However, the overall satisfaction of respondents on the policy implementation is very low, where only $28.4 \%$ and $3 \%$ indicated that they were satisfied or very satisfied respectively. Hence, the percentage of the respondents having mixed-feelings were very high with respect to the financial terms, policy implementation and role played by the policies in helping them to reach the market in commercializing their research products.

Table 9: Satisfaction with in Critical Issues in IP and Commercialization Policy

\begin{tabular}{|l|c|c|c|}
\hline \multicolumn{1}{|c|}{ Satisfaction Level } & $\begin{array}{c}\text { Financial terms in the } \\
\text { policy } \mathbf{( \% )}\end{array}$ & $\begin{array}{c}\text { The implementation of } \\
\text { the policy (\%) }\end{array}$ & $\begin{array}{c}\text { Policy's help towards } \\
\text { commercialization }(\boldsymbol{\%})\end{array}$ \\
\hline Very unsatisfied & 2.2 & 3.0 & 7.5 \\
\hline Unsatisfied & 13.4 & 16.4 & 17.2 \\
\hline Neutral & 53.7 & 49.3 & 38.1 \\
\hline Satisfied & 26.9 & 28.4 & 32.8 \\
\hline Very satisfied & 3.7 & 3.0 & 4.5 \\
\hline
\end{tabular}

Satisfaction with Communication Flow Related to IP and Commercialization

As shown in Table 10, the results indicated that only $26.9 \%$ and $32.8 \%$ were satisfied with the existing communication flow between researchers and the centres as well as between the relevant agencies and centres for IP and Commercialization of the research products respectively. As to whether communication flow is freed from the rigid protocol and the bureaucratic "red tape", only $28.4 \%$ of the respondents were satisfied. 
Table 10: Level of Satisfaction with Communication Flow in IP and Commercialization

\begin{tabular}{|c|c|c|c|c|}
\hline Satisfaction Level & $\begin{array}{c}\text { A proactive } \\
\text { communication } \\
\text { between the Centre } \\
\text { and researchers } \\
(\boldsymbol{\%})\end{array}$ & $\begin{array}{c}\text { Communication between } \\
\text { Centre and relevant } \\
\text { government agencies } \\
(\boldsymbol{\%})\end{array}$ & $\begin{array}{c}\text { Communication is free } \\
\text { from rigid protocol } \\
(\boldsymbol{\%})\end{array}$ & $\begin{array}{c}\text { Communication } \\
\text { via technology as } \\
\text { enabled tools } \\
(\boldsymbol{\%})\end{array}$ \\
\hline Very unsatisfied & 2.2 & 0.7 & 3.0 & 7.5 \\
\hline Unsatisfied & 13.4 & 16.4 & 16.4 & 17.2 \\
\hline Neutral & 53.7 & 46.3 & 49.3 & 38.1 \\
\hline Satisfied & 26.9 & 32.8 & 28.4 & 32.8 \\
\hline Very satisfied & 3.7 & 3.7 & 3.0 & 4.5 \\
\hline
\end{tabular}

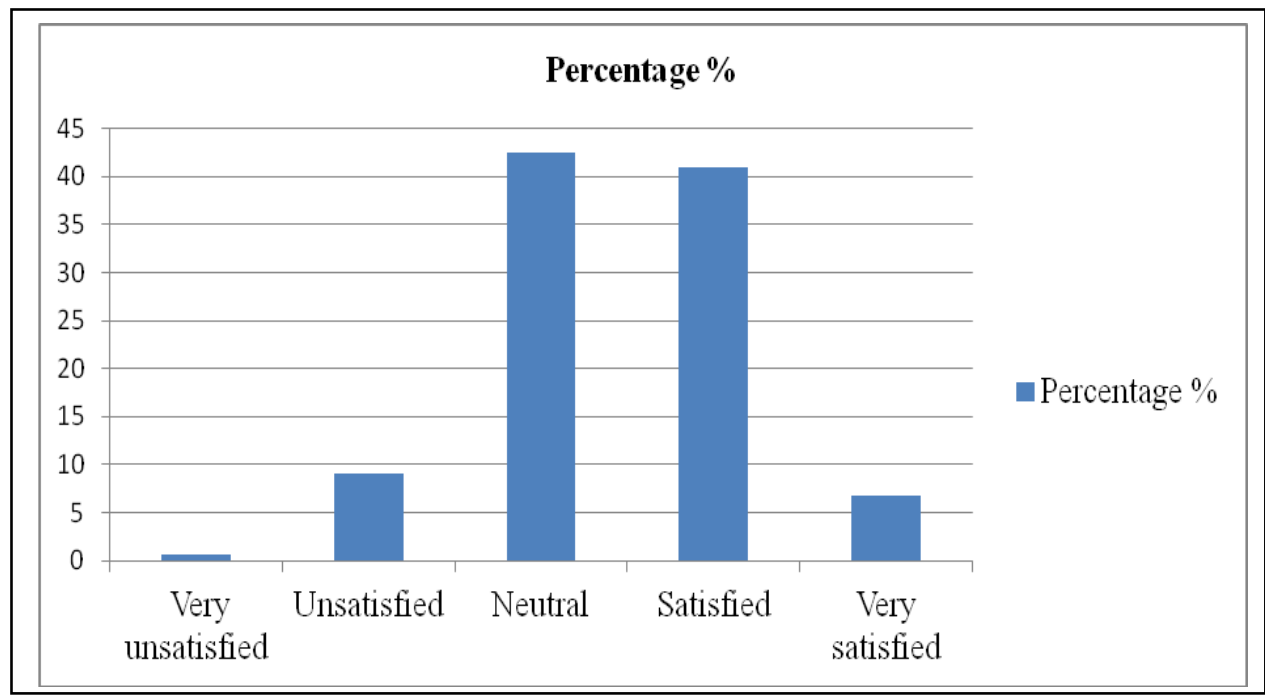

Figure 4: Overall Satisfaction Level with Communication Flow

However, a huge percentage of respondents indicated their mixed-feeling (42.5\%) about the wellness of communication flow related to IP and Commercialization of research products between researchers and the centres or between the agencies and the respective centres in various universities. In addition, the results also showed that only $32.8 \%$ of the respondents indicated the use of technology as enabled tools to enhance communication flow between researchers and the respective centres. It is worth noting that certain significant percentage of the respondents have shown their dissatisfactions with effective, proactive and rigid protocol in communication flow on IP and Commercialization of the research products (see Table 10). Overall, the results in Fig. 4 reflected a low percentage of very satisfactory level of communication-flow between researchers and the respective centres on matters related to IP and Commercialization of their research products.

\section{Structural Relations among the Constructs in the Model}

In this section, the researchers addressed the path coefficients to examine the relationships between the structural latent constructs of the model. The results obtained have shown positive significant relationships among all the constructs in the model.

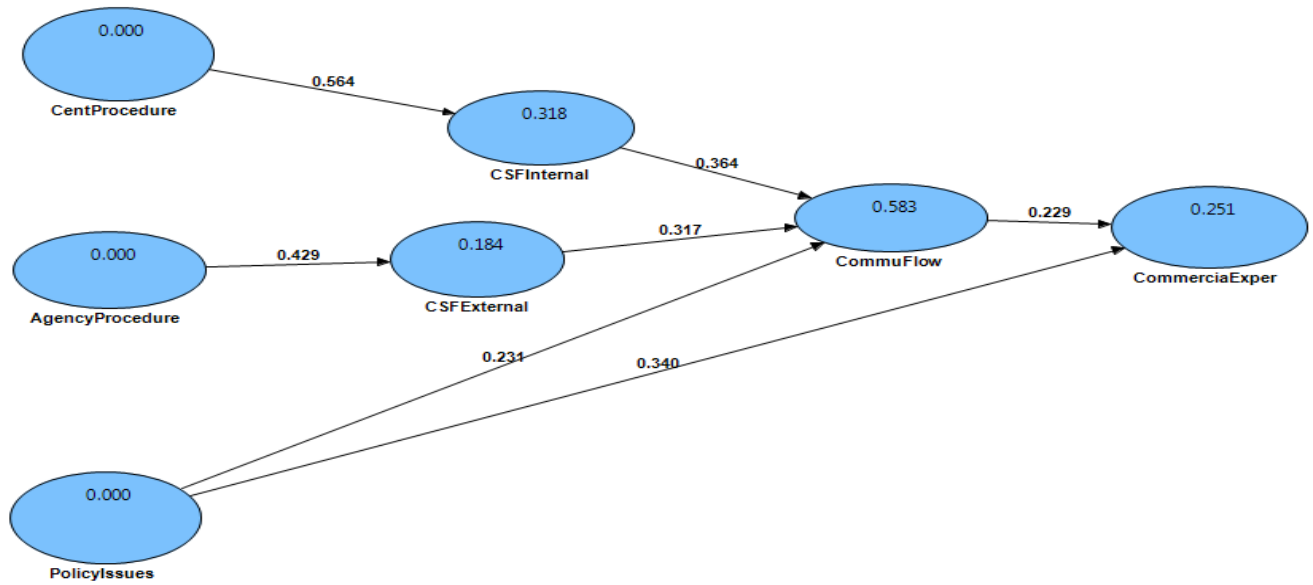

Figure 5: Structural Coefficient Results of the Model 
As clearly shown in Fig. 5, the results indicated a positive significant relationship between the IP and Commercialization procedures and internal critical success factors (CSFI) towards successful commercialization of the IP product at the centres with beta values of $0.564, p<0.001$. A similar significant positive relationship exists between the causal link of IP and Commercialization procedures and external critical success factors (CSFE) with beta coefficient values of $0.429, p<0.001$. In addition, both CSFI and CSFE have significant impact on communication flow related to IP and Commercialization of research product with a beta value of 0.264 and $0.317, p<0.001$ respectively. Furthermore, the path coefficients between policy issues in IP and Commercialization of products has shown a significant impact on communication flow and actual commercialization of the intellectual products with high beta value of 0.256 and $0.343, p<0.001$ respectively. The same similar positive causal link can be inferred between communication flow and the actual commercialization of the intellectual products with a beta value of $0.229, p<0.001$. Although the results in the figure has proven the significant relationships and ties among the key determinants of successful commercialization of intellectual products from research, yet there is also a need to examine the predictive capacity of the model developed in this study. The next section of the paper seeks to address this.

\section{Predictive Capacity of the Model and Hypotheses Testing}

As can be seen in Figure 6 that the t-value of the path coefficients are generated to test the significant contribution of each path coefficient of the latent constructs through a bootstrapping procedure in order to validate the predictive capacity of the extended model as well as the hypotheses put forward.

The results of the bootstrapping in the Figure 6 showed that hypotheses $\mathrm{H} 1$ and $\mathrm{H} 2$ in the study are supported with t-values ranging from $8.317 * * *$ to $6.903 * * *$ at an alpha-value less than 0.001 respectively. As the results depicted in the Table 11, the $R^{2}$ values of the two endogenous latent constructs in the model related to the causal links of the two endogenous variables which are 0.318 and 0.184 respectively. This indicates a significant influence of procedures at the agency and centre level on both the internal and external critical success factors of the centres in its efforts towards commercialization of the IP products. In addition, hypotheses H3, H4 and H5 of this study are with t-values of $1.808^{*}, 3.561^{* *}$ and $3.286^{* *}$ at an alpha level less than 0.05 and 0.001 respectively. Thus, the significant and practical effects of the elements of the three hypotheses in relation to the endogenous variable (communication flow) can be inferred from the $R^{2}$ value of 0.561 . Referring to Table 11 again, the results of the hypotheses H6 and $\mathrm{H} 7$ pertaining to the impacts of communication flow and policy issues on the success of IP commercialization were equally supported with t-values of $2.648^{* *}$ and $3.833^{* *}$. The magnitude of the impacts $\left(R^{2}\right.$-value) on the endogenous variable (actual commercialization experience) is 0.251 .

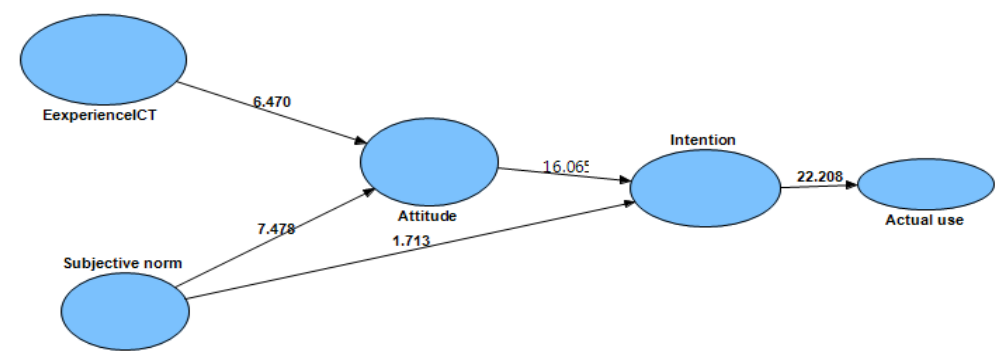

Figure 6: Bootstrapping Results of the Structural Model

According to Chin (1998), it is paramount to examine the predictive power of the model of the study based on the values of the various endogenous constructs obtained. According to Kock (2012), this can be possibly achieved by assessing the average variance inflation factor (AVIF) as a comprehensive analysis of a model's overall capacity and explanatory quality of the latent factors linking to actual commercialization of the IP products in this study. This is important in order to address the absence of both vertical and lateral 
collinearities. The result shows a value of 1.22 (see Table 11), which is far below the threshold of 3.3 (Kock, 2012; Ambali, 2013). Additionally, other indices for the model fit such as average path coefficient (APC), average r-squared (ARS) are equally addressed in the process of examining the predictive capacity of the model. In this respect, the results of both APC and ARS are $0.343 \%$ and $32.85 \%$ respectively. These results indicated a practical significant power of the model (Kock, 2012).

Table 11: Summary of T-Statistics of the Path Coefficients and Hypotheses Testing

\begin{tabular}{|c|c|c|c|c|c|}
\hline Hypothesis & $\begin{array}{c}\text { Construct }^{\text {a }} \\
\text { Causal Relation }\end{array}$ & $\begin{array}{c}\text { Beta }(\beta) \\
\text { Coefficient }\end{array}$ & $\begin{array}{c}\text { Endogenous Latent } \\
\text { Variables }\end{array}$ & T -Statistics & Remark \\
\hline H1 & CPRO -> CSFI & 0.564 & \multirow{2}{*}{$\begin{aligned} R^{2} & =0.318(31.8 \%) \\
R^{2} & =0.184(18.4 \%)\end{aligned}$} & $8.317 * * *$ & supported \\
\hline H2 & APRO -> CSFE & 0.429 & & $6.903 * * *$ & supported \\
\hline $\mathbf{H 3}$ & CSFI -> COMF & 0.264 & \multirow{3}{*}{$\begin{array}{l}R^{2}=0.561 \\
\quad(56.1 \%)\end{array}$} & $1.808^{*}$ & supported \\
\hline H4 & CSFE ->COMF & 0.317 & & $3.561 * *$ & supported \\
\hline H5 & $\mathrm{PI}->\mathrm{COMF}$ & 0.256 & & $3.286^{* * *}$ & supported \\
\hline H6 & COM->CIPE & 0.343 & \multirow{2}{*}{$\begin{array}{l}R^{2}=0.251 \\
(25.1 \%)\end{array}$} & $2.648 * *$ & supported \\
\hline H7 & PI->CIPE & 0.229 & & $3.833^{* *}$ & supported \\
\hline \multicolumn{6}{|c|}{ Predictive Capacity of the Model } \\
\hline \multicolumn{2}{|r|}{ Criteria } & \multicolumn{4}{|c|}{ Value } \\
\hline \multicolumn{2}{|r|}{ AVIF } & \multicolumn{4}{|c|}{1.22} \\
\hline \multicolumn{2}{|r|}{$\mathrm{APC}$} & \multicolumn{4}{|c|}{0.343} \\
\hline \multicolumn{2}{|r|}{ ARS } & \multicolumn{4}{|c|}{$32.85 \%$} \\
\hline \multicolumn{2}{|r|}{ Q-squared } & \multicolumn{4}{|c|}{0.41} \\
\hline
\end{tabular}

Note: $* * * p<0.001, * * p<0.01 ; * p<0.05$

Moreover, Q-squared coefficient was performed through blindfolding in order to assess the predictive validity associated with each latent variable block in the model as well as the strength. Acceptable predictive validity strength in connection with endogenous latent variables as suggested by examining the Q-squared coefficient must be greater than a zero threshold (Kock, 2012; Ambali, 2013). The result of the predictive validity for this model is 0.41 , indicating good predictive factors that can influence the actual commercialization of the research products.

\section{Conclusion}

Commercialization has become an important topic of discussion in an era where the results of university research may create opportunities for new processes and products. Despite the government's allocation of research grants to universities in developing countries such as Malaysia, the level of commercialization is still low. While numerous factors contribute to the poor commercialization rate, the internal dynamic management is one of the potential driving factors. These factors for successful IP and experience by the universities include: procedures, policy issues, critical success roles played by centres and agencies as well as the communication flow between researchers and centres managing the IP\&C. The findings indicated that all the identified key determinants towards successful entrepreneurial activities related to commercialization of research products are crucial and deserve due attention by various ministries and agencies as well as authorities at the universities. More importantly, the results from the interviewed session showed that management of the centres should be spearheaded by personalities from industry rather than academicians.

\section{Recommendations}

Based on the findings of the study, the following points are crucially recommended that:

1. The university should be business oriented to spearhead the centres for IP\&C for effectively discharging duties and achieving the goals of commercializing the research products. The fact that centers for IP \& Commercialization are still under the jurisdiction of academics at the universities may not yield any dynamic results.

2. There is an urgent need for reviewing the IP\&C procedures and simplify them for quick results.

3. There is also a need for policy reform related to IP\&C, especially to facilitate effective communication flow. It takes many years for most researchers to hear feedback about their products thereby making them develop intention to go directly to market on their own.

4. There is a need to relook into roles played by the centres and come out with new strategies such as collaborations with commercial industries pertinent to a particular research's product.

\section{Acknowledgement}

We wish to acknowledge the Higher Education Leadership Academy (AKEPT), Malaysian Ministry of Higher Education (MoHE) for the research grant enabling this study to be carried out. We also wish to thank all respondents who have willingly participated in the survey, research assistants, Tun Anum Shahbanum and Mohamad Azizi from the Research Innovation and Business Unit (RIBU), UiTM. 


\section{References}

[1] Ahmad, F. \& Krishna, V.V. (2006). The Science and The Technology System of Malaysia. Malaysian Website on S\&T and Other Sources, Malaysia, Putrajaya, Ministry of Science, Technology and Innovation.

[2] Ambali, A. R. (2013). Hala food and products in Malaysia: People's awareness and policy implications, Intellectual Discourse, 21(1), pp.732.

[3] Ambali, A. R., (2009a). E-government policy: Ground issues in e-filling system. European Journal of Social Sciences, 11(2): pp.249-266.

[4] Ambali, A. R. (2009b). Digital Divide and its implication on Malaysian e-government: Policy initiatives, in Rahman, H. (ed.) Social and political implications of data mining: knowledge management in e-government, pp.267-287, USA: IGI Global.

[5] Barclay, D. W., Higgins, C., \& Thompson, R. (1995). The partial least square approach to causal modeling: Personal computer adoption use as illustration, Technology Studies, 2(2), pp. 285-309.

[6] Brennan, M. C., \& McGowan, P. (2006). Academic entrepreneurship: An exploratory case study.

[7] Brennan, M. C., Wall, A. P., \& McGowan, P. (2005). Academic entrepreneurship. Assessing preferences in nascent entrepreneurs. Journal of Small Business and Enterprise Development, 12(3), 307-322.

[8] Chow W.S., \& Chan, L.S. (2008). Social network and shared goals in organizational knowledge sharing. Inf. Manage. 45(7):pp. 24-30.

[9] Chrisman, J. J., Hynes, T., \& Fraser, S. (1995). Faculty entrepreneurship and economic development: The case of the University of Calgary. Journal Business Venturing, 10(4), pp. 267-281.

[10] Clark, B.R. (1998). Creating entrepreneurial universities: Organizational pathways of transformation, International Association of Universities and Elsevier Science, Paris and Oxford.

[11] Compeau D.R, Higgins C.A, \& Huff S., (1999). Social cognitive theory and individual reactions to computing technology: a longitudinalstudy. MIS Q 23(2), pp. 145-158.

[12] Detert, J., Schroeder, R. \& Mauriel, J. (2000). A framework for linking culture and improvement, Academy of Management Review, 25(4), pp.850-863.

[13] Devine, S. (2005). The viable systems model applied to a national system of innovation to inform policy development. Syst Pract Action Res 18(5):491-517.

[14] Espejo R, \& Gill, A. (1997) The viable system model as a framework for understanding organizations.http://moderntimesworkplace.com/good_reading/GRRespSelf/TheViableSystemModel.pdf. Retrieved 18 August 2013.

[15] Etzkowitz, H. (1983). Entrepreneurial scientists and entrepreneurial universities in American academic science. Minerva, 31(3), 198-233.

[16] Etzkowitz, H. (2003). Research groups as 'quasi-firms': The invention of the entrepreneurial university. Research Policy, 32, pp. 109-121.

[17] Fornell, C., \& Larcker, D. F. (1981). Evaluating structural equation models with unobservable and measurement error. Journal of Marketing Research, 18(1), pp.39-50

[18] Hair J.F, Black W.C, Babin B.J, \& Anderson R.E. (2010) Multivariate data analysis. Prentice-Hall, Upper Saddle River

[19] Ireland, R. D., Kuratko, D . F. \& Morris, H. M., 2006. "A health audit for corporate entrepreneurship innovation at all levels: part 1," J. Business Strategy. 27 (1), pp. 10-17.

[20] Jacob, M., Lundqvist, M., \& Hellsmark, H. (2003). Entrepreneurial transformations in Swedish university system: The case of Chalmers University of Technology. Research Policy, 32(9), 1555-1568.

[21] Khairul Akmaliah, A., Hasmiah, K., Mohd Fuaad, S., \& Igel, B., (2012). "Functions and Inter-Relationships of Operating Agencies in Policy Implementation from a Viable System Perspective", Syst. Pract. Action Res., Vol. 25, pp. 149-170.

[22] Khairul Akmaliah, A, \& Mohd Fuaad, S., (2008). Technological innovation and firm development: the case of Infovalley_'s digital autopsy system commercialization. Asian Acad Manag 13(2):pp. 1-29.

[23] Kirby, D. A. (2006). Creating entrepreneurial universities in the UK: Applying entrepreneurship theory to practice. Journal of Technology Transfer, 31(5), 599-603.

[24] Kock, N. (2012). WarPLS 3.0, user manual. Laredo, Texas: ScriptWarp System.

[25] Martin, M.J.C. (1994). Managing innovation and entrepreneurship in technology-based firms. Wiley, New York.

[26] Martinelli, A. (2008). "Becoming an entrepreneurial university? a case study of knowledge exchange relationships and faculty attitudes in a medium sized research-oriented university," J.Technology Transfer, 2008, 33 (3), pp. 259-283.

[27] Moshe V., M.A. Satter and J. Pumwa, Okyay Kaynak, Guilherme Ary Plonski, Avitus M. Tibarimbasa, Eriabu Lugujjo, Michaela Martin (ed). (2007). The Management of University-Industry Relations: Five Institutional Studies from Africa,Europe, Latin America and the Pacific Region. Paris: UNESCO.

[28] Nagaretham, R., Mohd Shah, M.I.S., \& Ahmad Dahlan, A.R., (2012). "Comparison of Key Enablers for the Successful Commercialisation of Bioinformatics Products in Malaysia and Singapore", International Journal of Academic Research in Economics and Management Sciences, Vol 1 No 2, Apr, pp. 158-175

[29] Normah, O., (2011). "An Assessment of a University-Industry Partnership in a Malaysian University", International Journal of Business and Social Science, Vol 2 No 8, May, pp. 94-103).

[30] Phan, P. H., \& Siegel, D. S. (2006). The effectiveness of university technology transfer: Lessons learned from quantitative and qualitative research in the U.S. and the U.K. Rensselaer Working Papers in Economics, No. 0609.

[31] Podsakoff, P.M., Organ D.W. (1986). Self-reports in organizational research: problems and prospects. Journal of Management, 12(4), pp.531-544.

[32] Röpke, J. (1998). The entrepreneurial university, innovation, academic knowledge creation and regional development in a globalized economy. Working paper Department of Economics, Philipps-Universität Marburg, Germany, 15.

[33] Rothaermel, F.T., Agung, S.D. \& Jiang, I. (2007). "University Entrepreneurship: A Taxonomy of the Literature, Industrial and Corporate Change", Oxford University Press, Vol 16 No 4, pp. 691-791.

[34] Sekaran, U \& Bougie, R. (2010). Research methods for business: A skill building approach,(4th ed.). UK: John Wiley \& Sons, Inc

[35] Shane S, Venkataraman, S. (2000) The promise of entrepreneurship as a field of research. Acad Manag Rev., 25(1): pp. 217-226

[36] Sporn, B. (2001). Building adaptive universities: Emerging organizational forms based on experiences of European and US universities. Tertiary Education and Management, 7(2), pp. 121-134.

[37] Subotzky, G. (1999). Alternatives to the entrepreneurial university: New modes of knowledge production in community service programs. Higher Education, 38(4), 401-440.

[38] Sundbo, J., (1998). The theory of innovation: entrepreneurs, technology and strategy. Edward Elgar Publishing LTD, Cheltenham.

[39] United Nations Economic Commission for Europe (UNECE, 2011), Intellectual Property Commercialization: Policy options and practical instruments, New York and Geneva.

[40] Vigdor, M., Satter, M.A., Pumwa, J., Kaynak, O., Guilherme, A.P., Avitus, M.T., Eriabu, L., \& Michaela, M. (ed). (2007). The Management of University-Industry Relations: Five Institutional Studies from Africa, Europe, Latin America and the Pacific Region, Paris: UNESCO.

[41] Wind, J. and Main, J. (1999), Driving Change. The Free Press, New York, NY

[42] Yusof, M., \& Jain, K.K., (2010). Categories of University-Level Entrepreneurship: A Literature Survey, Int. Entrep. Manag. J., Vol 6, pp. $81-96$ 